\title{
The healing green, cultural synaesthesia and triangular comparativism
}

\author{
Elisabeth Hsu, University of Oxford
}

\section{Abstract:}

This article aims to make sense of the colour qing (green), and its materiality, as mentioned in a Chinese recipe for treating 'fatigue' (lao) with 'green' (qing) mulberry twig and other orchard trees' twig. What kind of fatigue was being treated by these green twig ingredients? If one treats the Chinese colour term's pronunciation as a phono-aesthetic aspect of a Chinese medical treatment, the Chinese 'sound of greenness' can be compared to the 'smell of greenness' that the Anangu people's medical practices effect in western Australia's desert after the first rains (Young 2005), and to how in early modern England young women of good standing started to develop and experience greene sycknesse in a gendered world (King 2004). As the 'triangular comparison' of these historically and culturally unrelated settings demonstrates, the respective greens - qing, ukiri and greene - are all an intrinsic aspect of body techniques that trigger lifeenhancing effects. By mobilizing Gestalt psychological insights further elaborated by Roman Jakobson and Brent Berlin, their effectiveness can be explained through human-plant configurations that produce a synaesthetic experience of colour.

There is a rich literature on colour symbolism and neo-Whorfian analyses of colour which elaborate on the different hues, intensities, brightness and saturation of culturally-specific colour terms. Indeed, as a disembodied universal, the colour green would 'symbolise' fertility. This article, however, steers away from the study of disembodied colour terms towards ethnographies of 'cultural synaesthesia' (Young 2005) and to an embodied understanding of colour as integral to 'material practice' (Young 2011b). I discuss a nexus of healing techniques that make use of fresh plants, and highlight how each of these greens is implicated into a different, culturally specific social configuration. By examining intercorporeal body techniques, this novel approach to the linguistic anthropology of colour contributes to an embodied understanding of phytocommunicability. ${ }^{1}$

The three colour terms for green, called qing, ukiri and greene, occur in the discussion of very different settings and practices, and they are completely unrelated to each other, geographically and historically. Qing refers to the shimmering green quality of certain ingredients of a Chinese recipe or, rather, a 'formula'; ukiri is the colour of the brilliant green tobacco leaf priced by Anungu women of western Australia; and greene sycknesse is a disorder that became prevalent in early modern England. So, why should one compare these three colour terms occurring in entirely different contexts with each other? The reason is a methodological one: Analogy and polarity is considered basic to reasoning since

\footnotetext{
1 The theoretical foundations I draw on are the Phenomenology of Perception (Merleau-Ponty [1945] 1962, 2012), and its introduction into medical, social and environmental anthropology (by Csordas 1994, Jackson 1996, Ingold 2000), which in turn provided the grounds for the research into the materiality of colour presented here (D. Young 2005, 2011a, 2011b). Phytocommunicability is here understood to refer to different possibilities of communication, primarily through sensory appreciation, from plants to human beings, and vice versa.
} 
Greek antiquity (Lloyd 1966), and arguably impossible to overcome (Descola 2013). Nevertheless, if one engages with a problem from three different angles, it may be possible to foreground forms of relatedness otherwise not perceived, such as asymmetrical relations, polythetic sets or gendered orientations. ${ }^{2}$

Triangular comparativism does not assume a 'messy reality', and accordingly, it is not actually interested in 'generalisation' (in the sense of Candea 2018:154, who cites Leach 1966:2). Rather, it aims to contribute to an anthropological 'path of translation' (contra reductionism, see Descola 2013:45-54) between different, but nevertheless comparable dynamic complexities. It does so by "starting from a practical engagement" (Descola 2013:68). Triangular comparativism works with the assumption that the world is infused with selfsimilarities and rhythms that trans-sect the usual dichotomies and hierarchies. This makes it possible to treat the above three colour terms for green (qing, ukiri and greene) as a co-constitutive element of human-plant relations and, specifically, as an aspect of social configurations that can be compared with each other.

'Triangular comparativism' is particularly useful for researching problems that are veiled in secrecy and/or vilified through stigma. It is regularly endorsed, without being named as such, when it is obvious that direct questioning for a quantitative assessment would yield distorted data. Thinking in a triangular way across continents and ages should furthermore overcome the constructed dichotomy between East and West, modern and premodern, and the like. ${ }^{3}$

Textual research into a Chinese recipe of the Song dynasty (960-1279) which was called the Five Twig Powder and listed twigs described as qing (bluegreen? / light green? / shiny translucent green?) kick started the triangular comparison presented here. ${ }^{4}$ The Song dynasty is characterized by a population

\footnotetext{
${ }^{2}$ For comprehensive discussion of comparison in anthropology, see Candea (2018).

3 'Triangular comparativism' hence contributes to what Descola (2013) calls 'symmetrical anthropology' challenging the Great Divide between moderns and non-moderns, and striving for a "reconciliation between the exotic and the familiar" (ibid: 71-72).

${ }^{4}$ The 'Five Twig Powder' (wu zhi san 五枝散) is one of the twelve recipes (or 'formulae')

for treating forms of fatigue that arise due to a state of depletion ( $x u$ lao 虛癆), listed in The Formulary kept by the Yang family (Yang shi fang) of 1178. The formula was found through computer searches for qing hao in the formulary literature from 168 BCE (the "Wushi'er bingfang") to 1911 (the abdication of the last Emperor). Among the 450 formulae in total, we have already translated ca. seventy Song dynasty formulae, and among those, five that resembled each other in structure and content (compared and contrasted in "How to read a recipe?", Hsu forthcoming).
} 
explosion due to newly introduced wet rice cultivation, ${ }^{5}$ resulting in both intensified urbanization and geographic expansion into Southern China, which was reviled for its miasmatic diseases (e.g. Chen 2014). Our focus will be on the materiality of the twig colour qing when compared with that of the greene of Greene sycknesse in early modern England (King 2004) and the ukiri brilliant green of wild tobacco among the Anangu women in Australia's Western desert (D. Young 2005).

\section{Wayfaring through the topography of the Five Twig Powder formula}

Reading is a situated practice (Ingold 2007), yet reading recipe texts is to date a barely theorized practice. Philology and the comparison of the same text in different editions is key to understanding a recipe text, this principle of textual scholarship is not questioned here. However, ethnographic fieldwork has shown that there are different attitudes to reading, as contemporary readers continue to engage in an 'active reading' of ancient texts by participating in the re-formulation of what they perceive their messages to be (Hsu 1999: chapters 3 and 4).

Wayfaring through a text is here proposed to refer to a particular kind of reading. Like Kathrin Lund (2005) is wayfaring through the mountainous landscape of the Scottish Highlands, a wayfarer through a text pays particular attention to irregularities in the physiognomy of a text's topography, i.e. the externalities of textual form. Wayfaring through the topography of a text means stumbling on occasion (is the word upon which one stumbled a matter of variatio, or is it indexical of a changed substratum?), stopping for taking a breath, looking back and taking multiple perspectives, enjoying changing views, and becoming sensitized to different layers of sediments with each their different strengths of support or resistance to one's step. Wayfaring is an immersive and interactive practice, an active and sensuous engagement with the text, and the reader pays attention to how the text affects themselves and their bodies. Does the text make me feel heavy, does it lift me up, is it rendering me confused or is it titillating and full of ironies?

At the turn of the $19^{\text {th }}$ to $20^{\text {th }}$ century, the Five Twig Powder was considered to treat consumption, a disorder not merely arising in the crowded dwellings of the inner city but also afflicting the beautiful and well-to-do (e.g. Dubos [1952] 1987). However, based on a wayfaring through the Five Twig Powder formula text, and stumbling across its irregularities, a reader may become

\footnotetext{
5 E.g. http://afe.easia.columbia.edu/songdynasty-module/tech-rice.html
} 
sensitized to the possibility that the $20^{\text {th }}$ century interpretation may be only one of many. It is possible, if not likely, that the recipe text may have grown over time. What looks like one treatment recommendation today might have come from different sources (Hsu forthcoming): the first part of the text presents a long list of ingredients, followed by instructions on how to prepare them, while the second part of this recipe text has a topography that is quite choppy. A wayfarer sensitive to the topography of the text may hypothesize distinctive layers of sedimented practices of prescription writing contained within it.

\section{The healing green}

The Five Twig Powder mentions first qing sang zhi, the bluegreen mulberry twig; shi liu zhi, the pomegranate twig; tao zhi, the peach twig; and mei zhi, the plum twig. It mentions later qing hao, identified today as both Artemisia annua and/or Artemisia apiacea, in English 'sweet wormwood'. What interests us here are the first four ingredients mentioned in this formula. They have in common that they are derived from twigs of cultivated trees (given that they are pharmaceutical ingredients they have been rendered as 'twig' above, rather than as 'twigs'). If we go into modern compendia of Chinese materia medica (e.g. Bensky et al. 2004) and formulae (e.g. Scheid et al. 2009), we note that none of the four twig ingredients is today in use. ${ }^{6}$ However, other plant parts of the same kind are used, namely sang pi 桑皮, Mori cortex; shi liu gen pi 石榴根皮; Granati Radicis Cortex; tao ren 桃仁, Persicae Semen; wu mei 烏梅, Mume Fructus. While the bark, the seed and the fruit of the same plants are nowadays in use, it is the twig ingredients that make up the Gestalt of the Five Twig Powder in the first line of the formula text. Three out of the four twig ingredients are derived from orchard trees, namely pomegranate, peach and plum.

As plum blossoms are the first to bloom in the year, it is not surprising that even today Chinese generally consider them indexical of purity, perseverance and renewal. Whenever I was doing fieldwork in China during spring time, my friends had me join them on visits to the parks or, better still, on their bicycle excursions out of the city to orchards in full blossom. Peach blossoms, in particular, were associated with love (while peach wood wards off evil and peach fruit enhances longevity). Finally, pomegranates, onwards from Adam and Eve in the garden of

\footnotetext{
${ }^{6}$ The discontinued practice of making use of orchard twig in Chinese medical prescriptions today is suggestive of its 'symbolic' significance in this recipe, whereas its 'empirical' effects may not have been sufficient for it to survive the test of time. This is said in awareness that thinking in such Cartesian dichotomies is always problematic (Ellen 2006).
} 
Eden (the pomegranate became the 'apple' in northern latitudes) have always been associated with fertility, East and West - no wonder, as they produce zillions of sweet red seeds.

Unusual in this formula is that the mulberry twig, which is mentioned first, should be qing (green, blue green or brilliant green'). Then, there is qing hao which means the 'green herb'. The greenness of both the orchard twig and the herb in this formula invokes freshness; combined with the scent of the fresh plants, the colour green synaesthetically reinforces the sense of freshness. Such freshness evidently was considered suited for treating the fatigue (lao) mentioned in the first line of the formula. Incidentally, the fifth ingredient mentioned, spring onion, is also remarkably green in comparison to other onions (e.g. the fistular onion). We will return to this ingredient at the very end of our discussion of this formula.

While fresh twigs of orchard trees in blossom would be praised for their distinctive, faint and fine, if not divine, scent, all four hundred Artemisia species have a strong and sometimes almost nauseating smell. $A$. annua, in particular, has a wonderfully sweet uplifting scent (personal experience). Accordingly, the 'sweet' in 'sweet wormwood' would refer to its scent rather than its taste. ${ }^{7}$ In standard modern Chinese, the term qing 青 is homophone with qing 清, pure and clean, and qing 輕, which means light (Hsu 2013); not only does the fresh plant qing hao effuse many ethereal oils, its name connotes an ethereal quality of lightness.

It is well known among ethnobotanists and anthropologists of the senses that offerings to gods and spirits are scented. As Howes (1991: 131-32) tells us, alongside a long list of other authors, they are certainly warranted in negotiations with them over the dying. Malinowski (1929: 449), thereupon cited, stated that among the Trobriand Islanders "magic, in order to achieve its greatest potency, must enter through the nose", given that "the sense of smell is the most important factor in the laying of spells on people". Radcliffe-Brown (1964: 311) remarked that on the Andaman Islands plant remedies for treating the ill "possessed of strong and characteristic odours" and that it was "through the odour that they effect a cure". Finally, Detienne (1977: 38) noted that thuos, as "one of the most ancient terms in the Homeric epic to refer to offerings to the gods", "originally had the sense of a 'substance burned in order to obtain a fragrant smoke'". Gell (1977:34) adds an experiential dimension to the above discussion by commenting on the

\footnotetext{
${ }^{7}$ The taste of A. annua leaf, stem, root and seed is bitter (personal experience, 2006, and various materia medica texts). A multimodal reading is also possible: sweet in sweet wormwood, just as in sweet peas, may have referred to both the scent and light green colour. The smell of qing hao was elsewhere described as a stench, namely the stench of the xin-cat, and probably apotropaic (Hsu forthcoming).
} 
"'atmospheric' modulation of waking experience" through scent and perfume. All these instances can be interpreted as instances of phytocommunicability as they involve human beings' sensory appreciations of plants.

In her ethnography on "The smell of green", Diana Young (2005) suggests the instances of the odiferous plant use she describes among the Anangu, specifically the Pitjantjatjara and Yankunytjatjara people, are a form of socially learnt synaesthesia that people embody and socially transmit. Synaesthesia is a neurological term, but Diana Young uses it in its basic sense of effecting a coming together of people's feelings and perceptions (although the term might in future be widened in a multi-species ethnography to include the feelings and perceptions of plants, animals, fungi and other living beings as well). Diana Young describes how the first rain drops in Australia's western desert after long periods of drought release a welcome smell from the earth that opens up and facilitates breathing, and how the ensuing prolonged rains turn the land into a 'brilliant green'. In her discussion of this culturally learned form of synaesthesia, she highlights how by means of its ingestion and absorption through one's skin, wild tobacco "turns you green and moist and new" (ibid.: 68), just like the greening of the surrounding desert. Women chew this wild tobacco, cherishing its strong odour and its very green colour, ukiri. It keeps their mouth moist, they say, and is especially valued for the endurance it engenders in singing during ritual. Diana Young does not mention nicotine here, as little as anyone would be explicit about the vitamin C contained in fresh shimmering green herbs, and yet these molecules can be seen as co-constitutive of the cultural synaesthesia described and they can also be comprehended as an integral to phytocommunicability.

To summarise, the fine, uplifting and ethereal scents of the brilliant green ingredients of the Five Twig Powder formula promise to have an enlivening effect not unlike that of the brilliant green wild tobacco that, mingled with the smell of the greening desert, facilitates Anangu women's breathing and enhances their perseverance in ritual singing. However, while the uplifting and enlivening similarities are striking, the ways in which the different brilliant green materialities constitute sociality are very different and situation-specific indeed.

\section{The materiality of colour}

When Diana Young (e.g. 2011a) speaks of the 'materiality of colour', she distances herself from the work of earlier ethnoscientists (e.g. Berlin and Kay 1969), whose research dealt with colour in a culturally rather disembodied and decontextualised way. Together with, yet also critical of, relativist linguists she 
emphasizes the cultural situatedness of the specific things that are considered to have colour. This is evident in her discussion of the wild tobacco mentioned above, and also of 'bush medicine number one' called irmangka-irmangka, a 'lovely green' that saturates the heated animal fats which in massage sessions are rubbed into the body. The large lush leaves of the tobacco and the warm green fats which are constitutive of vitality-enhancing massage techniques would be difficult to account for in comparative studies of cross-cultural psychology; even if one takes account not merely of the colour's hue, but also of its intensity and brightness, and its saturation. The intricate embeddedness of the smell of green in such specific sociocultural practices defies, as Diana Young claims, meaningful cross-cultural comparison.

Regardless, Young's ethnography speaks clearly, albeit indirectly to the triangular comparativist. As already hinted at above, in China, the homophone words qing 青 'green', qing 輕 'feeling light' and qing 清'pure, clean and translucent' can jointly create a comparable [synaesthetic] expectation. The twig, if used in a fresh and greenish state, may well have been experienced as constitutive of a materiality that enlivens and uplifts.

It is striking that the sound of qing, ukiri and green is pitched and high. Ethnobotanists have long pointed out that the sound of plant names may not be arbitrary. As Brent Berlin (1992: 232-259) noted, the structuralist linguistic assessment of them as onomatopoetic expressions does not do justice to this wide-spread phenomenon. He suggested that the sound yi or ee encourages the drawing of zigzagged sharp lines, while sounds like o and a encourage people to draw round lines. He presented a diagram (p. 233), based on Wolfgang Köhler's (1929) description of takete (for the figure with zigzagged lines) and maluma (for that with the round lines), which became widely known through Roman Jakobson ([1979]1987), whose late oeuvre centred on how the sound of words related to their meaning. Relevant to us here is that, according to Plato, Socrates already associated the sound $i$ with smallness and lightness (ibid.: 187). While it is obvious that this observation cannot entertain sweeping claims to universality, we will examine situated and experience-near ethnographic evidence with this in mind below.

The $y i$ and ee in these words for green point to an expectation about these green things as sharp and fresh, uplifting, alighting and enlivening. Natural scientists likely will focus on the electromagnetic spectrum and note that human beings perceive as green those (leftover) waves that the plant leaf's chlorophyll does not absorb, but the phytocommunicability we discuss here has more to do with the interactive practices that led human beings to implicate fresh, i.e. green 
plants into their preventive medical and healing efforts. The plants' green freshness and scent effected a synaesthesia that was reinforced by the physiological effects of chemicals such as the psychotropic nicotine or the antioxidant ascorbic acid. ${ }^{8}$ How exactly these cultural phenomena came into being, historically, remains a conundrum. Triangular comparativism can only point in direction of the Gestalt of the social configurations that prompted plants and people into making them happen.

How green is the healing green?

Greene sycknesse (King 2004), also known by its Greek name chlorosis, seems to contradict all the healthful connotations of green established above for the ethnobotanicals in the Asia-Pacific region. First, we note that the colour green is in this compound word an attribute of a disorder and not of a healing herb. Furthermore, the sound of the Greek word, chloros, is not a yi but an $o$. If, as G. E. R. Lloyd (1996) so often noted, people in ancient China and Greece went about solving comparable problems in very different ways, is chlorosis the relativist linguist's and cultural constructivist's antidote to the argument that is being developed here? (The argument is that the plant's colour and the human sound of the words that refer to it, may both have material qualities that evoke comparable dispositions to and expectations about it).

Illnesses, sicknesses, local biologies and dis-ease, are highly complex phenomena that arise in the context of specific socialities, and King's monograph makes this point convincingly: chlorosis was, contrary to its Greek name, not an ancient Greek disease. Furthermore, it barely had semblance with the Hippocratic "disease of virgins", although claims were made to that effect. King (2004) provides convincing evidence that it was a new disease which plagued mostly adolescent girls in England from between the mid-sixteenth to the early twentieth century. It presented in a wide range of symptoms that changed with medical author and over the centuries, including in general the absence of the menstruation and also a dieting on "perverse foods", or none at all, and all this gave rise to "passive, weak, innocent, beautiful and suffering victims" (ibid.:8). However culturally constructed green sickness was, Helen King follows Irvine Loudon (1980) in claiming that it had "family resemblances" with anorexia nervosa today.

\footnotetext{
${ }^{8}$ Chemical ingredients are decontextualized in bioscientific accounts, while the anthropology of cultural synaesthesia should not shy away from mentioning them. Rather than treating those molecules as the lone 'pharmacologically active substance', they should be accounted for as part of a larger process of creating a cultural synaesthesia.
} 
In a similar vein, let us ask whether it is possible to formulate an argument that insists on resemblances between the different greens discussed so far and their perceived healing capacities? Obviously, the Greek word chloros with its omega and omicron as dominant vowels differs in sound from qing and ukiri. However, as King (2004:19-21) demonstrates, chlorosis was not actually the name of the disorder. It was a "technical name", invented by a medic, while the actual name of the disorder, which was already half a century earlier in circulation, was the English "green sickness". Incidentally, unlike the Greek word chloros, we note that the English word green has an ee that is like in qing and ukiri fronted and raised. So, the question is now: might the 'green' of 'green sickness', despite the above, nevertheless have been considered uplifting and healing too?

In the section "How green was green sickness?", King tells us that the shades of green connoted by this sickness ranged from pale and livid to white and translucent. This colour range barely instills the impression of a healing green. However, King (ibid.:7) also quotes a physician describing the patient's complexion having a 'beautiful rosy-red tint', although after the flushing that the encounter with the physician caused, her face apparently became 'pale'. More importantly King (ibid.:13) notes elsewhere that "the direct evidence of the senses was considered very important when the sick girl was observed by her physician and found to be 'green'", but King also points to contradictions thereby raised between 'theory and observation'. Evidently, King is doubtful that the name of this sickness had anything to do with the patient's outward signs and symptoms.

So, how should we understand the 'green' in 'green sickness' if it did not refer to the 'green' complexion of the patient? King (ibid.:149) mentions a textual source that claims it is a term that it derives from the Arabic agriaca. However, as she notes, this word sounds more Latin or Greek, and neither g nor $\mathrm{c}$ is a phoneme in Arabic. In this context, King also mentions an Arabic word that sounds similar, aghariqa. She then comments, somewhat dismissively: "This would be a remedy rather than a disease". Indeed, according to King, aghariqa was a powerful purgative that would have induced menstruation, and, like other purgatives, it may indeed have been indicated for treating the symptoms of green sickness. Medical anthropology has widely documented that a remedy can become the word by which people refer to the illness. Furthermore, in Chinese medical texts the remedy was regularly read as a shorthand for the diagnosis of a medical condition (e.g. Andrews 2001). Indeed, it is well-known that there is a hesitation among physicians to name a sickness, particularly if stigma is involved, and if they name it, they do so only in very general terms. It is conceivable that naming the remedy was the usual mode of referring to medical conditions also in some pockets of the Arabic and Latin medical worlds. 
Early on, medical anthropology has made use of a particularly useful concept for making sense of the problem we are tackling here: the 'illness taskonomy' (Nichter [1988] 1996). Accordingly, Western biomedicine formulates 'disease taxonomies' based on an investigation into the cause of the disease in past history. By contrast, popular and folk medical illness labels contain within them indications for the strategy of how to treat them, which Nichter rightly presents as socially more effective. To a certain extent the distinguishing patterns (bian zheng) in Chinese medicine have features of such 'illness taskonomies'. For instance, although the distinguishing pattern feng han gan mao is often translated as 'a common cold caused by wind and coldness', as though it was a diagnosis (a taxonomy), the term actually contains information on how the physician should treat the condition, i.e. it relates the treatment strategies that should be endorsed (a task-onomy), namely remedies classified as combating wind and coldness. Nichter's Cartesian dichotomy between taxonomies and task-onomies has the advantage that it can highlight that a Chinese medical 'distinguishing pattern' has semblance not only with diagnostic categories, but also with folk medical 'illness labels' in that it contains within its name the hint of a socially acceptable and approved treatment strategy.

In a similar vein, we may now understand the term 'green sickness' not as a medical scientific and taxonomic term but as an illness label of common folks. So, to answer the question 'what is healthful about 'green' in 'green sickness'?', we shall now suggest that both the sound and semantics of the word green hint at treatment strategy. Folk wisdom was that the healing of this sickness's 'green' lay in its consummation: for adolescent girls, marriage was a 'sovereign cure'! In many cases, it would not only be uplifting, and even exhilarating, but also life giving.

Herewith it has been possible to demonstrate that however linguistically layered and historically complex the social configuration in question is, the ee in the 'green' of 'green sickness' may not be mere coincidence. There is perhaps a valid argument to be made that the human ee sound for a plant's situation-specific healing green is constitutive of its life-engendering meaning.

\section{Budding twigs for budding maidens?}

Returning to the Anangu in Australia's western desert, with the complications in mind that green sickness caused for some adolescent girls in the gendered worlds of early modern England, Diana Young's (2005: 68) beautiful prose suddenly gains contour as it too contains hints that the smell of green is part 
of a gendered pluriverse. Thus, Young states, after noting that kangaroo food is reserved for men, that the chewing of tobacco, called mingkulpa, is the most desired bush produce for women in particular: "The plants grow at the base of rocky outcrops under the shade of fig trees at the mouth of caves or at the edges of creek beds". And she notes: "Women hide their own minkulpa store, but the quid carried between lips and teeth is visible", hinting at a titillating if not flirtatious quality of how the quid's shiny green is mediating social relations.

Accordingly, the triangular comparativist now finds herself re-examining the Five Twig Powder in regard of gender issues. Perhaps, the powder made of budding twigs may have treated a fatigue which, not unlike green sickness in early modern England, was afflicting 'budding' virgins in Song dynasty China? The phrase zhi san qu lao 枝散取勞 'twig powder removes fatigue', mentioned in the first line of the text, is still contained within the verbosity that the formula accrued over many centuries. Might it be that the formula made of the fresh and budding mulberry, pomegranate, peach and plum twig ingredients was primarily for treating a fatigue affecting adolescent girls? Through triangular comparativism a gendered reading of the Song dynasty formula has become possible that was not originally anticipated!

Remains the spring onion: yes, it is green, it has a pungent smell, but perhaps not quite as strong as that of any other onion. Why make use of it? The formula recommends grating all ingredients in a section detailing how to prepare the remedy. It states in the first line of a long paragraph on how to prepare the recipe: yi shang bing chuo 已上並轨 'grate the above in unison'. So, might the hollow of the onion stalk have been used as a container and been filled with a 'powder' consisting of grated orchard twig? The triangular comparativist is reminded in this context of the minkulpa, the Anangu women's priced brilliant green chewing tobacco. The adolescent young women would then have had a healthful, green 'chewing gum' of a spring onion stuffed with grated orchard twig! Indeed, there is evidence to suggest that chewing orchard twigs may not merely have been revitalising and refreshing for the young women but also erotically meaningful. ${ }^{9}$

\section{Discussion}

By attending to colour as an aspect of material practice (Young 2011b) and by recording practices that enable moments of 'cultural synaesthesia' (Young

\footnotetext{
${ }^{9}$ Taiwanese girls gave their preferred lover a chewing gum, as Taylor (1999) recorded in $19^{\text {th }}$ century Taiwan. With many thanks to Prof. G. Dudbridge (pers. communication, 2015).
} 
2005), we have moved away from making claims about colour terms as disembodied universals. Instead, triangular comparativism has foregrounded distinctive social configurations and their perceived Gestalt. Specifically, triangular comparativism has been an eye opener for interpreting the Five Twig Powder. In the early $20^{\text {th }}$ century this formula may well have been used for treating consumption, naturally without providing a cure for this terminal disease, but in the Song dynasty, the formula may have been articulated around a gendered experience of dis-ease among adolescent girls which could be effectively treated.

Triangular comparativism furthermore made it possible to suggest that the materiality of the colour terms greene, ukiri and qing mattered in so far as the sound of their pronunciation mattered. I suggested that the sound of these words, pronounced with a fronted and raised vowel, is co-constitutive of a synaesthetically comprehended Gestalt of treatment. The plants' greenness - as in the case of the three herbal remedies of the wild tobacco mingkulpa, of possibly Aghariqa and of the fresh mulberry twig qing sang zhi - is best comprehended as constitutive of specific human-plant configurations which have refreshing, uplifting and enlivening effects. Although each fresh green plant was implicated into a different social configuration, they all appear to have been implicated into situations where the flirtatious, playful and erotic aspects of gendered relations would matter. By attending to the materiality of colour, it has been possible to show how healing techniques can implicate humans and plants into a mutually attuned, complex and nuanced nexus thanks to phytocommunicability.

\section{Bibliography}

Andrews, B.J. (2001) From Case Records to Case Histories: the Modernisation of a Chinese Medical Genre, 1912-49, in E. Hsu (ed.) Innovation in Chinese Medicine. Cambridge: Cambridge University Press, 324-336.

Bensky, D., Clavey, S. and Stöger, E. with Gambler, A. (2004) Chinese Herbal Medicine: Materia Medica. $3^{\text {rd }}$ edition. Seattle, WA: Eastland Press.

Berlin, B. (1992). Manchung and Bikua: the Non-arbitrariness of Ethnobiological Nomenclature, in B. Berlin Ethnobiological Classification: Principles of Categorization of Plants and Animals in Traditional Societies. Princeton: Princeton University Press, Chapter 6: 232-259.

Berlin, B. and Kay, P. (1969) Basic Color Terms: Their Universality and Evolution. Berkeley: University of California Press.

Csordas, T. J. (1994) Embodiment and Experience: The Existential Ground of Culture and Self. Cambridge: Cambridge University Press.

Descola, P. (2013) The Ecology of Others. Chicago: Prickly Paradigm Press.

Detienne, M. (1977) The Gardens of Adonis: Spices in Greek Mythology. Princeton: Princeton University Press.

Chen Yunju (2014) Zhang (Miasma), Heat and Dampness of the South: Environmental Experience in Textual Knowledge of Song Medicine (9601279). DPhil thesis in Oriental Studies, University of Oxford. 
Dubos, R.J. and J. [1952] (1987) The White Plague: Tuberculosis, Man, and Society. New Brunswick: Rutgers University Press.

Ellen, R. (2006) Introduction. Ethnobiology and the Science of Humankind. Special Issue. The Journal of the Royal Anthropological Institute 12, S1-S22.

Gell, A. (1977) Magic, Perfume, Dream, in I. Lewis (ed.) Symbols and Sentiments. London: Academic Press, 25-38.

Howes, D. (1991) Olfaction and Transition, in D. Howes (ed.) The Varieties of Sensory Experience: a Sourcebook in the Anthropology of the Senses. Toronto: University of Toronto Press, Chapter 9: 128-147.

Hsu, E. (1999). The Transmission of Chinese Medicine. Cambridge: Cambridge University Press.

Hsu, E. (2012) "Feeling lighter": Why the patient's treatment evaluation matters to the health scientist. Topical Review Article. Integrative Medicine Research 1(1): 5-12.

Hsu, E. (forthcoming) "How to Read a Recipe? Working Backwards from the Prescription to the Complaint", in U. Steinert (ed.) London: Routledge.

Hsu, E., Wu, Z. P., Zhou, X. F., Yang, W. Z., Sun, X., Peng, W. H. (in preparation) Handbook of qing hao Recipes (from the first to the twentieth century).

Ingold, T. (2000) The Perception of the Environment: Essays on Livelihood, Dwelling, Skill. London: Routledge.

Ingold, T. (2007) Lines: A Brief History. Abingdon: Routledge.

Jackson, M. (1996) Things as They Are: New Directions in Phenomenological Anthropology. Bloomington: Indiana University Press.

Jakobson, R. ([1979] 1987) The Sound Shape of Language. $2^{\text {nd }}$ ed. Berlin: de Gruyter.

King, H. (2004) The Disease of Virgins: Green Sickness, Chlorosis and the Problems of Puberty. London: Routledge.

Köhler, W. G. (1929) Gestalt Psychology. New York: Liveright Publishing Corp.

Lloyd, G.E.R. (1966) Polarity and Analogy: Two Types of Argumentation in Early Greek Thought. Bristol: Bristol Classical Press.

Lloyd, G.E.R. (1996) Adversaries and Authorities: Investigations into Ancient Greek and Chinese Science. Cambridge: Cambridge University Press.

Loudon, I. S. L. (1980) Chlorosis, Anaemia, and Anorexia Nervosa. British Medical Journal 281(6256): 1669-1675.

Lund, K. (2005) Seeing in Motion and the Touching Eye: Walking over Scotland's Mountains. Etnofoor 18(1): 27-42.

Malinowski, B. (1929) Practical Anthropology. Cambridge: Cambridge University Press.

Merleau-Ponty, M. ([1945] 1962 resp. 2012) Phenomenology of Perception, translated by R. Smith, resp. translated by D. A. Landes. London resp. Abingdon: Routledge.

Nichter, M. ([1989]1996). Health Social Science Research on the Study of Diarrheal Disease: A Focus on Dysentery, in M. Nichter \& M. Nichter (eds.) Anthropology and International Health: South Asian Case Studies. Amsterdam: Overseas Publishers Association, Chapter 4: 111-134.

Radcliffe-Brown, A. R. (1964). The Andaman Islanders. New York: Free Press. 
Scheid, V., Bensky, D., Ellis, A. and R. Barolet (compiled and transl.) (2009) Chinese Herbal Medicine: Formulas \& Strategies. $2^{\text {nd }}$ edition. Seattle, WA: Eastland Press.

Taylor, G., Dudbridge, G. ed. (1999) Aborigines of South Taiwan in the 1880s: Papers by the South Cape Lightkeeper George Taylor. Edited and with an introduction by Glen Dudbridge. Shung Ye Museum of Formosan Aborigines Monograph Series 2. Taipei: Institute of Taiwan History, Academia Sinica.

Young, D. (2005). The Smell of Greenness: Cultural Synaesthesia in the Western Desert. Etnofoor 18(1): 61-77.

Young, D., (2011a) Mutable Things: Colours as Material Practice in the Northwest of South Australia. Journal of the Royal Anthropological Institute 17(2): 227443.

Young, D., (2011b) The Colours of Things, in C. Tilley, W. Keane, S. Küchler, M. Rowlands and P. Spyer (eds) Handbook of Material Culture. Sage Knowledge, Chapter 11: 173-185. http://dx.doi.org/10.4135/9781848607972.n12

\section{Primary sources in Chinese}

Yang shi jia cang fang 楊氏家藏方 (Formulae kept by the Yang family). Song, 1178. By Yang Tan 楊倓. References to the print of 1777 in Japan (Anei year 6, 安 永六年).

\section{Acknowledgements}

This article elaborates on long term research since 2011 on the herbal antimalarial qing hao 青蒿, Artemisia annua L. This article elaborated on research presented in 2014 in Cambridge, 2015 at Oxford, 2016 in Berlin, and 2017 via skype for Rutgers University, USA. I thank my audiences for their engaging critique, as well as Francesca Rochberg, David Parkin, and the two anonymous reviewers for their most sensitive comments and precise editorial recommendations. 


\section{楊氏家藏方·卷第十·虛勞方一十二道·五枝散·三頁}

Formulae kept by the Yang family: twelve formulae for depletion-induced fatigue: The Five Twig Powder (chapter 10, p. 3)

The green colour refers to a textual layer hypothesized to be an early one, the bluegreen colour to a textual layer considered to have been added later, and the red colour refers to comments hypothesized to have been added by a host of 'active readers' (for more detail, see Hsu forthcoming).

\section{五枝散}

取一切傳屍勞䖝

The Five Twig Powder (wu zhi san)

takes away all kinds of contagious corpse conditions, fatigue and worms.

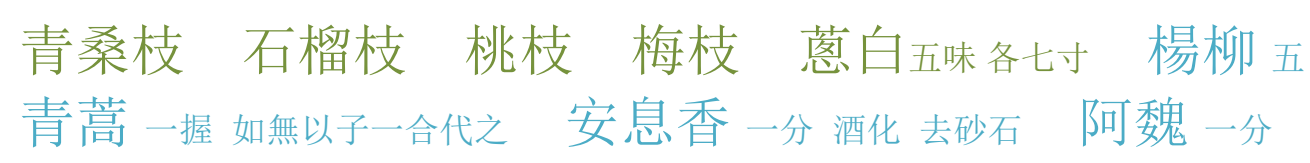

Bluegreen mulberry twig (qing sang zhi), pomegranate twig (shi liu zhi), peach twig (tao zhi), plum twig (mei zhi), spring onion (cong bai) of these five flavours each seven cun [7× $3.12 \mathrm{~cm}$ in the Song dynasty];

willow (yang liu) five [shoots]; sweet wormwood (qing hao), onebunch, if you do not have any [fresh material], take one ge $[1 \times 67 \mathrm{ml}]$ of seed to replace it; benzoin (an xi xiang) one $f e n[1 \times 0.4 \mathrm{~g}]$, dissolved in wine, with sand and stones removed: devil's dung $(a$ wei) one $f e n[1 \times 0.4 \mathrm{~g}]$.

\section{已上除阿魏 餘並坐 用小便一升半煮諸藥 耗及一半 去諸藥滓 將藥汁化阿魏 再煮十數沸 再濾去㳯 放溫 分作二服 調後藥}

Regarding the above with the exception of devil's dung ( $a$ wei): put the remaining together and chop. Use one and a half sheng $[1.5 \times 670 \mathrm{ml}]$ of children's urine to boil all the medicines. Reduce by half. Remove the residue of all the medicines. Take the juice from all the medicines to dissolve the devil's dung (a wei). Bring it again ten times to boiling point. Filter it again and remove the residue. Set it aside to let it go warm [i.e. cool down]. Divide into two doses. Harmonise with the following medicines:

\section{朱砂 別研半兩 檳榔末 半兩 謝香 別研半分}


cinnabar (zhu sha) separately pounded, half a liang [0.5 $\times 40 \mathrm{~g}$ ]; betel nut powder (bing lang mo) half a liang $[0.5 \times 40 \mathrm{~g}]$; musk (she xiang) separately pounded, half a fen $[0.5 \times 0.4 \mathrm{~g}]$.

右三味為細末 研極匀 分二服 用前藥汁調下五更初一服 三點再一服 辰巳間取下䖝 急以鐵鉗投熱油鐺內煎之 可絕 根本 如見䖝色白者 此病必安 如帶黑色 斯已傳入臓 不 可療也 服藥後只以淡籿補之 並不動元氣 效驗無比 切須 秘之大凡病傳屍者 必須先服此藥取䖝 然後隨證調治 不 可一概用藥 如初取下虫色已黑 縱服妙藥亦無補也 然猶能 使不傳它人

Make the above three ingredients into a fine powder. Pound until they are of absolutely equal consistency. Divide into two doses. Use the above medicinal juice to harmonise and flush them down [i.e. excrete them]. At the beginning of the fifth geng [3-5am] administer one [dose]; at the third point administer one dose again; between chen (7-9am) and si [9-11am] remove and flush down the worms.

[Added comments of hypothetical 'active readers']:

i. Quickly use tweezers to throw them into hot oil inside a frying pan to fry them. This allows one to sever them from their roots and origins.

ii. If one sees that the worms' colour is white then this disorder certainly is safe [and under control]. If they carry a black hue, then the [disorder] is already being transmitted to and has entered the viscera, and it is not possible to treat it.

iii. After administering the medicines only use bland porridges to supplement [the patient]. If one does not stir the original qi, the effectiveness is proven to be without comparison.

iv. All of this must be kept secret!

v. Generally those who suffer from a contagious corpse condition must necessarily first administer this medicine to take away the worms, then, in accordance with the evidence [of the condition's overall pattern], harmonise and treat [it].

vi. One should not use any medicines consistently in the same way.

vi. If, as one starts to remove and flush down the worms, their colour is already black, then even if one continued to administer the miraculous drug, it still would be of no avail [to the patient]. However, one can still effect that there is no transmission to another person. 
Composition of the polypharmacy (excerpts from Hsu et al, in prep.; based on Bensky et al. 2004, whose identification regards contemporary materia medica). N.B. The identification of the botanical species in ancient texts is not reliable.

\section{[1] 五枝散 The Five Twig Powder (wu zhi san), 1178}

青桑枝/ qing sang zhi/ Morus alba/ bluegreen [fresh?] mulberry twig

石榴枝/ shi liu zhi/ Punica granatum/ pomegranate twig, see suan shi liu 酸石榴 桃枝/ tao zhi/ Prunus persica, P. davidiana/ peach twig

梅枝/ mei zhi/ Prunus mume/ plum twig

葸白/ cong bai/ Allium fistulosum/ spring onion

楊柳/yang liu / Salix babylonica/ willow

青蒿/ qing hao/Artemisia apiacea, A. annua/ sweet wormwood

安息香/ an xi xiang/Styrax benzoin, S. tonkinensis/ benzoin

阿魏/ a wei/ Ferula assa-foetida, F. caspica, F. conocaula/ devil's dung, asafoetida 辰砂/ chen sha/ HgS, cinnabar / cinnabar

檳榔末/ bin lang mo/Areca catechu/ betel nut powder

鹿香/ she xiang/Moschus moschiferus/ musk 